\title{
Importancia del aislamiento social en la pandemia de la COVID-19
}

\section{Importance of social isolation in the COVID-19 pandemic}

\section{Señor Editor:}

Los gobiernos podrían minimizar el impacto de la COVID-19, así como las consecuencias del impacto en los sistemas de salud. Mantener la tasa de letalidad lo más baja posible será la máxima prioridad para las personas; por lo tanto, los gobiernos deben establecer medidas urgentes para evitar su propagación (1). Muchas preguntas sobre el coronavirus se podrían hacer, es muy difícil tomar una decisión sobre qué hacer hoy. ¿Deberías esperar más información? ¿Hacer algo hoy? ¿Qué?, ¿Cuántos casos de coronavirus habrá en su área?, ¿Qué pasará cuando se materialicen estos casos?, ¿Qué deberías hacer?, ¿Cuándo? Teniendo en cuenta que el nuevo coronavirus tiene aún pocos meses en el mundo y existen muy pocos estudios sobre él. El objetivo de esta carta es dar a conocer la importancia del aislamiento social en Perú.

El aislamiento social y alerta sanitaria para evitar la congregación de personas (suspensión de clases en colegios, universidades e institutos) y el énfasis en el lavado de manos son las principales medidas que el gobierno peruano ha tomado. Lo que se busca con estas medidas es que el número de infectados que se conviertan en casos graves puedan ser manejados y tratados por la precaria capacidad que cuenta nuestro sistema de salud. El Perú ha sido por lo menos un tanto agresivo al dar sus medidas sanitarias antes que otros países de Sudamérica (gráfico 1) (2). El gobierno peruano además ha planteado la cuarentena de los pasajeros que provienen de zonas como España,

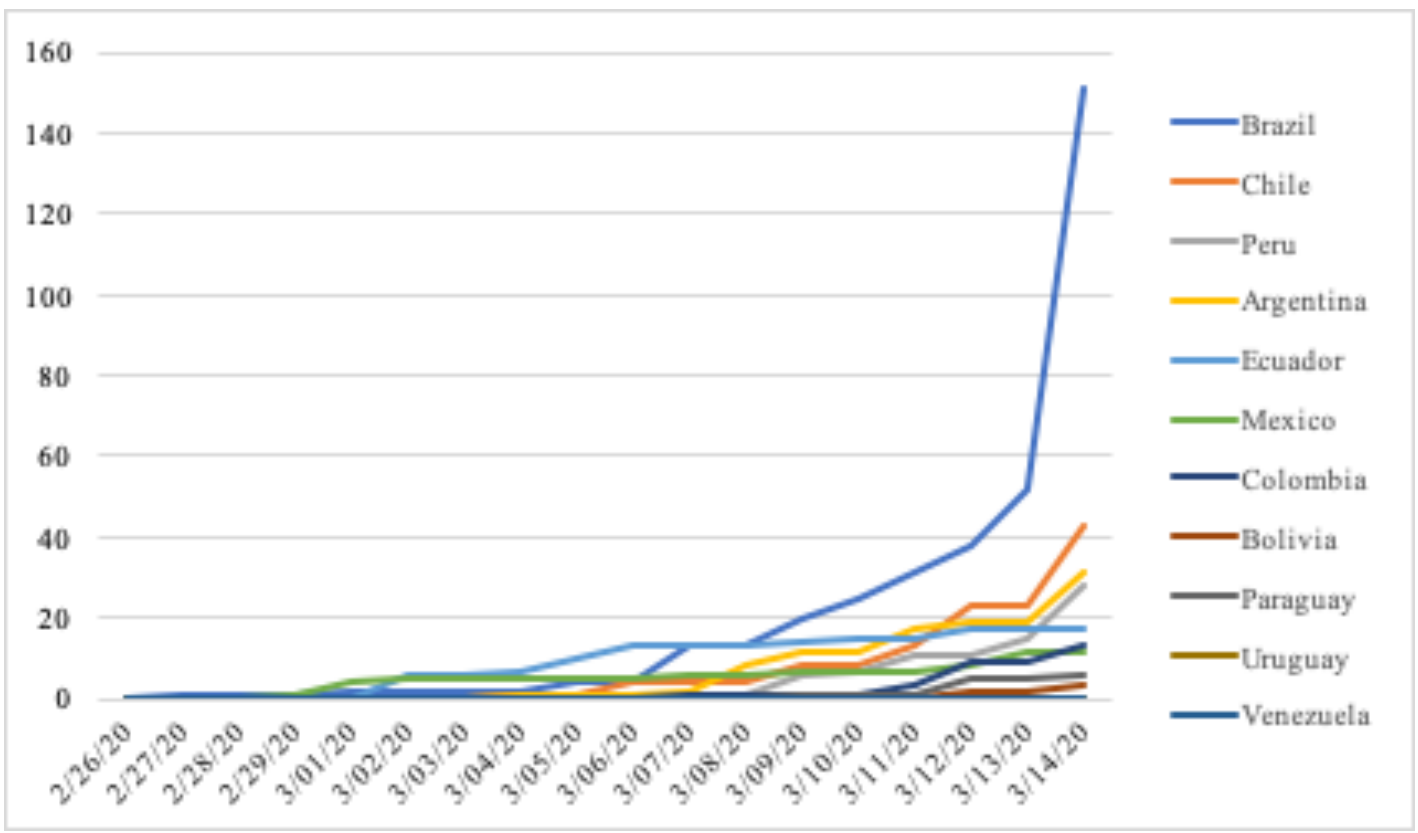

Gráfico 1. Número de casos de personas con la COVID 19 en Sudamérica (2).

Facultad de Ciencias Biológicas, Universidad Nacional Pedro Ruiz Gallo. Lambayeque, Perú.

a Biólogo, Egresado

b ORCID: https://orcid.org/0000-0002-4984-4656 


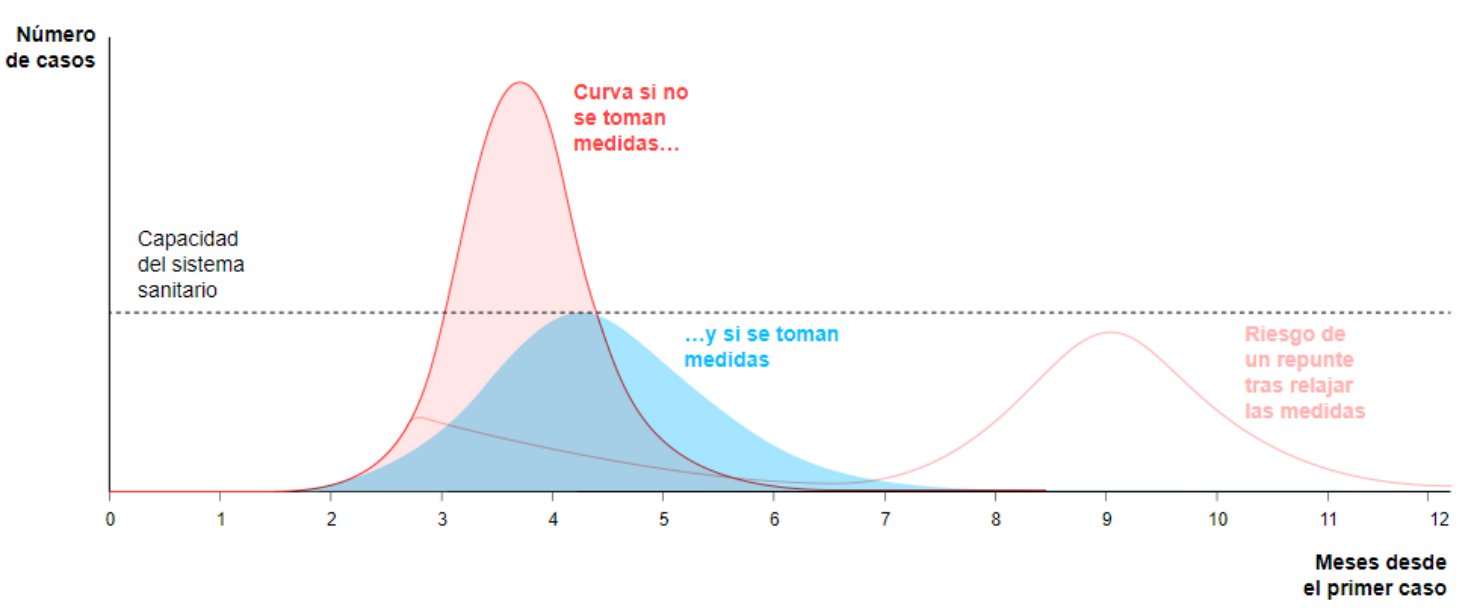

Gráfico 2. Simulaciones ilustrativas de un modelo de transmisión de la COVID-19 (4).

Italia y China. Estas medidas han sido bien aplicadas no fueron los únicos factores que propiciaron la propagación en nuestro país.

En el gráfico 1 se explica la simulación de línea en base a aislamientos de casos solamente (rojo); una simulación con distanciamiento social en su lugar a lo largo de la epidemia, hay un aplanamiento de la curva (celeste), y una simulación con distanciamiento social más efectivo en su lugar durante un período limitado como el caso de Perú, se verá una epidemia resurgente cuando se detiene la norma de distanciamiento social en unos meses (rosado) (1). El comportamiento individual será crucial para evitar y controlar la propagación de COVID-19. Las acciones personales, más que la acción gubernamental será más importante. Autoaislamiento, búsqueda de asesoramiento médico de forma remota, el distanciamiento social y lavado de manos son la clave. Las acciones del gobierno peruano para prohibir las aglomeraciones de personas masivas son importantes, al igual que las buenas instalaciones de diagnóstico junto con el tratamiento especializado para personas graves (3). Si las medidas se relajan después de unos meses para evitar un impacto económico severo, es probable que se produzca un nuevo pico en otoño (grafico 2) (4). Se concluye que se debe de seguir las medidas gubernamentales de aislamiento por un tiempo más prolongado.

\section{Sebastian Iglesias-Osores ${ }^{1, a, b}$}

\section{Correspondencia:}

Sebastian Iglesias-Osores,

Correo electrónico: email: sebasiglo@gmail.com ;

siglesias@unprg.edu.pe

\section{REFERENCIAS BIBLIOGRÁFICAS}

1. Anderson RM, Heesterbeek H, Klinkenberg D, Hollingsworth TD. How will country-based mitigation measures influence the course of the COVID-19 epidemic? Lancet. 2020; 1:0-0. DOI: https://doi.org/10.1016/S0140-6736 (20)30567-5

2. CSSE at Johns Hopkins University. CSSEGISandData/ COVID-19. Baltimore: CSSE at Johns Hopkins University; 2020. (Citado el 15 de marzo del 2020) Disponible en: https://github.com/CSSEGISandData

3. Ministerio de Salud. Plan Nacional de Preparación y Respuesta frente al riesgo de introducción del Coronavirus 2019-nCoV", Lima: Ministerio de Salud; 31 de enero del 2020

4. El País. Objetivo número uno: aplanar la curva del coronavirus. Madrid: EL PAÍS. 11 de marzo del 2020 (Citado el 19 de julio del 2020). Disponible en: https://elpais.com/ciencia/2020-03-11/objetivonumero-uno-aplanar-la-curva-del-coronavirus.html

Recibido: 19/03/2020

Aceptado: 05/07/2020 